\title{
Estrategias culturales al servicio de la diplomacia chilena: La misión de José Antonio Soffia en Bogotá, 1881-1886
}

\section{Cultural Strategies at the Service of Chilean Diplomacy: The Mission of José Antonio Soffia in Bogotá, 1881-1886}

\author{
Juan David Murillo Sandoval ${ }^{1}$ \\ Pontificia Universidad Católica de Chile (Chile)
}

Recibido: 31-01-17

Aprobado: 18-04-17

\section{Resumen}

Este artículo analiza el papel diplomático-cultural de José Antonio Soffia, Enviado extraordinario y Ministro plenipotenciario chileno radicado en Bogotá entre 1881 y 1886 . Teniendo entre sus objetivos mejorar la imagen de Chile en Colombia y prevenir su intromisión en los planes asociados al triunfo en la Guerra del Pacífico, se plantea que Soffia buscó ganar el favor de la élite política y letrada colombiana por medio de estrategias culturales. Conocedor de los gustos literarios de la clase política local, Soffia aprovechó su vocación como poeta para vincularse con esta, promoviendo proyectos editoriales, espacios de sociabilidad e intercambios de libros. Ejercido durante cinco años,

\footnotetext{
${ }^{1}$ (jdmurillo@uc.cl). Candidato a Doctor en Historia por la Pontificia Universidad Católica de Chile. Sus líneas de investigación abarcan la historia del libro y la historia intelectual latinoamericana. Integra el Grupo Nación/Cultura/Memoria de la Universidad del Valle. Entre sus publicaciones recientes destacan: "De lo natural y lo nacional. Representaciones de la naturaleza explotable en la exposición internacional de Chile de 1875" (Historia, 2015); "Entre o Industrial e o Intelectual: Os Livros nas Exposições Universais e o Campo Gráfico Latino-Americano" (Livro, 2015); y "La confección del Diccionario biográfico obrero de Chile. Cultura impresa y sociabilidad obrera a comienzos del siglo XX" (Iberoamericana, 2016). Es autor de "El Estado como librero. Políticas oficiales y cultura impresa en Colombia, 1821-1886" (2016), capítulo del libro Minúscula y plural: cultura escrita en Colombia. Este artículo forma parte del proyecto "Conexiones libreras. Modernización y cultura impresa entre Argentina, Chile y Colombia, 1880-1920", financiado por CONICYT en el marco de la beca de Doctorado nacional 2013-63130178. Una primera versión de este texto se presentó en el XVII Congreso Colombiano de Historia, Bogotá, 2015.
} 
este accionar le ganó el favor del medio letrado capitalino, que cambió su opinión negativa frente a Chile y que incluso, luego de su repentina muerte en 1886, le homenajeó como a uno de los suyos por sus diversos aportes a la cultura nacional.

Palabras-clave: José Antonio Soffia, Diplomacia chilena, Colombia, Guerra del Pacífico, diplomacia cultural, Ateneo de Bogotá.

\begin{abstract}
This paper seeks to analyze the diplomatic and cultural role of José Antonio Soffia, the Chilean Extraordinary Envoy and Plenipotentiary Minister based in Bogotá between 1881 and 1886. In order to improve Chile's image in Colombia and prevent its intrusion into the plans contemplated by the Chilean government at the end of the Pacific War, the text argues that Soffia sought to win the favor of the Colombian political and literary elite through cultural strategies. Knowing the literary tastes of the political class, Soffia took advantage of his vocation as a poet to link with it, promoting publishing projects, spaces of sociability and exchanges of books. Exercised for five years, this action won him the favor of the lettered circles, which changed his negative opinion against Chile and even honored Soffia, after his sudden death in 1886, as one of his own for their various contributions to Colombian culture.
\end{abstract}

Key-words: José Antonio Soffia, Chilean Diplomacy, Colombia, War of the Pacific, Cultural Diplomacy, Ateneo de Bogotá.

\title{
Presentación
}

Como dominio que interroga las relaciones internacionales desde una perspectiva sociocultural, los estudios de diplomacia cultural han contribuido en las últimas décadas a un entendimiento más profundo de los procesos de circulación e intercambio de ideas y saberes entre configuraciones estatales distintas $^{2}$. Privilegiando fuentes tanto oficiales como alternativas, que han redirigido la atención hacia espacios y mediadores de la cultura antes no relevados, este campo ha abierto nuevas pistas para el estudio de la comunicación internacional, de sus múltiples canales y de sus resultados en el tiempo, yendo más allá del lente político que suele envolver este tipo de relacionamientos.

2 Pascal Ory, Introduction [en Anne Dulphy, Robert Frank, Marie-Anne Matard-Bonucci y Pascal Ory, dir.: Les relations culturelles internationales au XXe siècle. De la diplomatie culturelle à l'acculturation, Bruselas, P.I.E. Peter Lang, 2010], pp. 15-23. 
Entre otras disciplinas, la historia intelectual y la historia del libro han tenido un papel importante en la transformación de este campo. Alineadas con perspectivas como la transferencia cultural, estas han logrado poner el foco sobre aquellos fenómenos de contacto e interacción que, escapando de los muros de cancillerías y embajadas, tuvieron repercusiones en el plano de la cultura. Así, las iniciativas editoriales de migrantes y exiliados, las estrategias de propaganda en contextos de tensión política, o el aliento dado a la traducción de determinados géneros o autores, entre otros fenómenos de movilidad transnacional, ocupan hoy una plaza importante entre los intereses de los historiadores.

Para el caso latinoamericano, la otrora tradicional vinculación de los hombres de letras al ejercicio diplomático, notable en itinerarios como los de Rubén Darío, Miguel Cané, Sanín Cano o Gabriela Mistral, ha sido reproblematizada por los historiadores del mundo intelectual, quienes además de aportar a la reconstrucción de las iniciativas particulares de estas figuras, han ilustrado también sus roles como mediadores culturales ${ }^{3}$. La perspectiva histórico-intelectual ha mostrado así que las transacciones en el ejercicio diplomático ponen en juego toda una suerte de bienes simbólicos que no responden necesariamente al deber ser de la actividad.

En un sentido inverso, algunas investigaciones dedicadas al mundo de la edición han evidenciado que el trabajo de algunos actores editoriales puede provocar la movilización de los canales políticos internacionales. En un clima de Guerra Fría cultural, por ejemplo, Gustavo Sorá ha demostrado cómo la maquinaria diplomática puede incidir sobre el manejo interno de las empresas editoriales, una vez este provoca malestares en los espacios de poder locales y extranjeros ${ }^{4}$.

En otras experiencias, los libros han sido el centro mismo del contacto. En la segunda mitad del siglo XIX, en paralelo a la modernización de las bibliotecas nacionales, el canje de libros entre los estados latinoamericanos fue una de las formas de intercambio cultural más recurrentes. Inaugurada por oficiales de instrucción y proto-bibliotecarios, esta práctica determinó el inicio de comparaciones entre las producciones oficiales, jurídicas y científicas de cada país, así como la imitación de aquellos modelos considerados convenientes. Asunto poco explorado, los canales institucionales del libro constituyen una de las aristas del relacionamiento cultural interamericano.

\footnotetext{
${ }^{3}$ Jorge Myers, Los intelectuales latinoamericanos desde la colonia hasta el inicio del siglo XX [en Carlos Altamirano, dir.: Historia de los intelectuales en América Latina, volumen I, Buenos Aires, Katz Editores, 2008], p. 41. Myers califica a la diplomacia como "la profesión por antonomasia de los intelectuales".

${ }^{4}$ Gustavo Sorá, Édition et politique. Guerre froide dans la culture latinoaméricaine des années 60 [en Claude Hauser, Thomas Loué, Jean-Yves Mollier y François Vallotton, Eds.: La diplomatie par le livre: Réseaux et circulation internationale de l'imprimé de 1880 à nos jours, París, Nouveau Monde, 2010], pp. 89-113.
} 
Situado en estas perspectivas articuladas, este artículo busca iluminar un itinerario diplomático en su dimensión cultural, el de José Antonio Soffia (1843-1886). Establecido en Colombia como Enviado Extraordinario y Ministro Plenipotenciario de Chile entre 1881 y 1886, Soffia dejó a su paso un interesante número de obras e iniciativas individuales y colectivas que marcaron la vida cultural bogotana durante el lustro que duró su ejercicio. De forma general, se plantea que con el fin de defender los intereses geopolíticos chilenos y mejorar la imagen de su país en Colombia, magullada por la Guerra del Pacífico, Soffia buscó seducir la opinión del mundo letrado y político -para este momento una misma unidad-por las vías del trabajo intelectual.

Conocedor de la estrecha relación entre poder y escritura en el país, Soffia aprovechó su propia vocación como poeta para acercarse a las élites letradas, promoviendo con ellas intercambios de libros, proyectos editoriales y espacios de sociabilidad. Focalizadas en momentos y sobre actores específicos, estas tareas le ganaron el favor de los círculos políticos capitalinos, que cambiaron su opinión desfavorable frente a Chile y que incluso llegada la muerte del diplomático en 1886 le homenajearon como a uno de los suyos por sus aportes a la cultura nacional.

En contraste con la positiva imagen que Soffia dejó en Bogotá, la que el diplomático transmitió a su país sobre la política colombiana estuvo lejos de ser elogiosa. En sus cartas a los presidentes chilenos Aníbal Pinto y Domingo Santa María, el ministro criticó el giro conservador de la década de 1880, así como de los autoritarios esfuerzos de Rafael Núñez (1825-1894) por desmantelar el modelo instaurado por el liberalismo radical. Enmarcado en la constitución de 1863, que había otorgado a Colombia una silueta federal y un núcleo de libertades plenas de prensa y asociación, el modelo radical era visto por Núñez como el origen de la inestabilidad política del país, factor que le llevaría a dejar sus primigenias banderas liberales para abrazar el conservatismo.

Devenido en el proceso conocido como la Regeneración, el proyecto de Núñez y del elenco conservador instalará las bases de un régimen nuevo, que destacará por su naturaleza centralista, su autoritarismo y su férreo catolicismo, elementos todos que convergerán en la constitución de 1886, y que, como veremos, inquietaron de sobremanera al ministro chileno 5 . Durante la guerra civil de 1885, que enfrentaría de nuevo y no por última vez a las facciones liberales y las conservadoras, Soffia llegará incluso a pedir su retiro de Colombia, país que calificaba como una sombra delirante de lo que había sido a inicios del siglo.

\footnotetext{
5 Sobre los principios de la Regeneración y sus referentes intelectuales: Miguel Ángel Urrego, Intelectuales, Estado y Nación en Colombia. De la guerra de los mil días a la constitución de 1991, Bogotá, Siglo del Hombre Editores - Universidad Central-DIUC, 2002, pp. 41-52.
} 
Con base en este doble panorama, el artículo destaca el lugar de las estrategias intelectuales para fijar opiniones y alcanzar objetivos en el campo de la política internacional, $y$, junto a ello, las visiones de un representante extranjero que asistió a los comienzos de una de las transiciones más importantes de la historia política colombiana. Antes que separar el análisis de lo intelectual y de lo diplomático, tal como otros acercamientos al itinerario de Soffia han hecho, buscamos aquí relevar la complementariedad de ambos ejercicios. Dividido en tres partes, el artículo repasa primero la trayectoria de Soffia, explora el contexto que motivó su nombramiento y examina sus primeros pasos en Bogotá. Seguidamente, se analiza el aprovechamiento de su vocación poética y también su rol como estimulador del mundo impreso bogotano en el alcance de sus objetivos, para luego analizar sus opiniones frente a la situación política del país, las cuales exponen su distancia frente a un escenario con el que compartía gustos pero poco más.

\section{"La propaganda va bien": Sociabilidad, prensa y opinión}

Nacido al interior de una familia de comerciantes en 1843, y nieto por línea materna del prócer de la independencia José Gregorio Argomedo, José Antonio Soffia ganó pronto un lugar en el restringido espacio literario chileno. Educado en el Instituto Nacional, Soffia publicó sus primeras composiciones en periódicos como La Voz, La Revista de Sud-América, el Correo Literario, La Revista Ilustrada y Estrella de Chile. En este último, Soffia será un colaborador constante, alcanzando una alta recordación por composiciones como Las Cartas de mi madre, la más famosa de sus producciones publicada en marzo de $1873^{6}$.

En paralelo al crecimiento de su popularidad literaria, y luego de un breve paso como funcionario de la Biblioteca Nacional en Santiago, Soffia incursionó en la política. Sobre la década de 1870 ejerció, por ejemplo, los cargos de intendente de Aconcagua, diputado suplente por Petorca, y subsecretario del ministerio de Interior, sin lograr afianzarse o destacar en ninguno ${ }^{7}$. Los procesos derivados del inicio de la Guerra del Pacífico (1879-1883) marcaron, no obstante, un notable giro en sus relaciones con la institucionalidad. Aunque no tomó parte en ningún acontecimiento bélico, Soffia hizo uso de su vocación poética para rendir homenajes a las tropas, arengando los navíos que zarpaban al frente, o bien participando de recitales fúnebres en honor a los soldados caídos ${ }^{8}$.

\footnotetext{
${ }^{6}$ Raúl Silva Castro, Introducción [en Poemas y poesías de José Antonio Soffia. Selección y estudio crítico por Raúl Silva Castro, Santiago de Chile, Imprenta Universitaria, 1950], pp. 13-27. Del mismo autor: José Antonio Soffia (1843-1886), Santiago, Andrés Bello, 1968.

${ }^{7}$ Ibidem, pp. 57-60.

8 Ibídem, p. 10. En los medios impresos, destacarán algunas composiciones nacionalistas como
} 
Parte de una maquinaria mayor de expresiones nacionalistas derivadas de la guerra, las actividades de Soffia sumaron a su reconocimiento literario, y fueron vistas con aprecio por parte del Estado chileno, que ante los giros favorables en la contienda comenzaba a planear nuevas estrategias de cara al espacio internacional. Como han destacado Raúl Silva Castro y Mauricio Rubilar, una vez el triunfo militar sobre Perú y Bolivia comenzaba a hacerse patente (el ejército chileno ocupó Lima en 1881), Chile abrió un nuevo frente en el que las plumas se privilegiarían por sobre los fusiles ${ }^{9}$. Descuidada según algunos publicistas del periodo, la política internacional chilena pasó a una fase de gran actividad con el objetivo de fijar opiniones favorables a su conducta, regionalmente sancionada, y defender los planes concebidos para finalizar a su manera la guerra.

El nombramiento de Soffia como Ministro plenipotenciario en Colombia respondió a estas ansiedades. El país austral concebía vital ganar posiciones a su favor dentro del continente, todo con miras a evitar conductas que imposibilitaran su accionar geopolítico sobre Perú y Bolivia. En este sentido, la diplomacia chilena estuvo especialmente alerta de la opinión colombiana. Le preocupaba la cercanía de parte de sus líderes con los EEUU, así como el tráfico de armas hacia Perú por vía panameña. Preocupaba también la simpatía hacia los países derrotados, que había decantado en la idea de convocar un Congreso Internacional y una convención de arbitraje para dar un fin balanceado a la guerra. Las instrucciones dadas a Soffia giraron alrededor de estas cuestiones. El enviado debía contrarrestar las actitudes negativas y sembrar en Bogotá una opinión favorable al camino de acción fijado por Chile en la postguerra, en breve: su anexión de las provincias peruanas y bolivianas ricas en minerales.

Llegado a Colombia en abril de 1881, junto a su esposa y a la vez prima Lastenia Soffia, y también junto al secretario de la legación, el señor Manuel J. Vega, el nuevo Ministro plenipotenciario tuvo de entrada buenas expectativas sobre su misión. En sus primeras cartas al entonces presidente Aníbal Pinto, Soffia expresaba comodidad y optimismo frente al estudio que adelantaba de los partidos colombianos, de la diplomacia local y de la prensa. A su vez, y ante el desconocimiento que afirmaba notar en Bogotá sobre la Guerra del Pacífico,

Tarapacá, El soldado chileno o La Ilíada del Pacífico, las cuales acompañarán las noticias derivadas de la Guerra.

9 Ibidem, pp. 87-89. Aunque Silva Castro destaca tempranamente este factor, resulta ineludible referir a los trabajos de Mauricio Rubilar, quien ha profundizado sobre la política internacional chilena de la postguerra del Pacífico y sobre el propio actuar de Soffia. Véanse: Guerra y diplomacia: las relaciones chileno-colombianas durante la guerra y postguerra del Pacifico (1879-1886), "Revista Universum", 19, 1 (2004), pp. 148-175; y su tesis doctoral inédita: La política exterior de Chile durante la guerra y postguerra del Pacifico (1879-1891): las relaciones con Estados Unidos y Colombia. Diplomacia, opinión pública y poder naval, Tesis para optar al Grado de Doctor por la Universidad de Valladolid, Valladolid, 2012. 
comunicaba a Santiago lo oportuno de haber llevado consigo ejemplares de $\mathrm{La}$ Historia de la Guerra del Pacífico (1880) de Diego Barros Arana, libro que concebía ideal para enfrentar "una opinión pública mal informada"10.

De esta manera, proveyendo lecturas, Soffia empezó a relacionarse con la que será el blanco de su accionar: la "sociedad ilustrada". Llegado durante el primer gobierno de Rafael Núñez (1880-1882), y viviendo en pleno la administración de Francisco Javier Zaldúa (abril a diciembre de 1882), Soffia asistió a un momento idóneo para analizar la vida política colombiana, logrando avanzar rápido en su comprensión del escenario, de los protagonistas, de las fuerzas en disputa y de los órganos de comunicación. A seis meses de su arribo, en septiembre de 1881, un Soffia orgulloso de su conocimiento de la prensa local hará alarde de los primeros logros.

En carta dirigida al nuevo presidente chileno Domingo Santa María, el ministro mencionaba: "Las simpatías de la opinión y de la prensa en favor nuestro, me hacen estar sumamente complacido en este país. Los periódicos más importantes nos son adictos: 'La luz', 'La unión', 'El relator', y 'El deber'" ${ }^{\prime}$. En la misma misiva, Soffia relevó un asunto adicional: la escritura por parte de José María Samper, por entonces pieza clave del proyecto conservador, de una semblanza del propio presidente Santa María. "Con más o menos criterio", explicaba al mandatario, "Samper se ha aprovechado de nuestros datos"12. En efecto, el diplomático había entregado a Samper las fuentes para la escritura de esta obra, que publicada inicialmente en El deber, sería luego impresa en la forma de folleto. Según insinuaba Soffia, este era el primer gran paso en torno al direccionamiento de la opinión local.

La importancia de esta obra residía en sus calificaciones. Samper caracterizaba a Santa María como un pensador, un hombre de libros, cuya llegada al poder daba testimonio del carácter civilista del país austral. Según Samper, Santa María había llegado a la presidencia gracias al respaldo de un partido liberal moderado y a un clima de opinión favorable a su perfil humanista, dos elementos que le garantizaron su triunfo por sobre el candidato rival, el general Manuel Baquedano, un notable héroe de guerra. La puesta en circulación de este texto, por uno de los referentes políticos e intelectuales del conservatismo, fue sin dudas un logro temprano de Soffia. El perfil construido de Santa María atacaba la idea de Chile como país belicista, difundiendo por el contrario la imagen de una república que prefería al letrado por sobre el hombre de armas ${ }^{13}$.

\footnotetext{
${ }^{10}$ Sobre esta práctica, agregaba Soffia: "Me piden todos, con intereses, el trabajo de Barros Arana y otras publicaciones sobre la guerra, pues las que traje han sido muy estimadas", en: Archivo Nacional de Chile (ANC), Colección Domingo Santa María González (DSMG), doc. A6767, José Antonio Soffia (Soffia, en adelante) a Aníbal Pinto Garmendia, Bogotá, mayo 5 de 1881.

${ }^{11}$ ANC, Colección DSMG, doc. C3160, Soffia a Domingo Santa María, Bogotá, septiembre 5 de 1881.

12 Ídem.

13 José María Samper, Chile y su presidente (Rasgo político-biográfico), Bogotá, Imprenta de
} 
Con esta última idea, Samper lanzaba además dardos al radicalismo colombiano y sus cabecillas, en su mayoría experimentados jefes militares. Según explicaba, la llegada al poder de Santa María, aunque impulsada por el liberalismo chileno, exponía el triunfo de la "filosofía conservadora". Preferir al candidato "civil", al "humanista", en un momento de peligro para la libertad y la estabilidad, afirmaba Samper, era un acto "profundamente conservador"14. De este modo, y gracias la ayuda de con Soffia, Samper propagaba un acervo de ideas positivas sobre Chile al tiempo que construía una relación en la cual conservatismo, poder letrado y estabilidad política iban de la mano ${ }^{15}$. Este interesado uso de una figura político-intelectual extranjera anticipaba uno de los criterios de la Regeneración, la de llevar al poder un perfil delineado por la erudición y el dominio de la lengua, facultades administradas por la élite conservadora.

La articulación entre los intereses de Soffia y los anhelos del conservatismo continuaría. A un mes de publicado este libro, en octubre, José A. Soffia impulsaría nuevas estrategias de acercamiento y atracción intelectual. Ya empapado de los hábitos de las élites bogotanas, y quizá consciente de lo oportuno de su propia vocación poética, Soffia planeó la realización de una tertulia-mosaico en su casa. Para ello, dirigió a distintas personalidades una invitación en forma de soneto esdrújulo con el objetivo de que cada asistente respondiera en rima idéntica. Lleno de elogios para los nacionales, el soneto apelaba a la "simpática costumbre" del mosaico bogotano, advirtiendo en su primera estrofa que no habría en la reunión ninguna "liturgia diplomática".

La invitación fue contestada en prosa o verso según la experticia de cada figura. Nombres como los de José Joaquín Ortiz, José Manuel Marroquín, Rafael Pombo, Diego Fallon, Miguel A. Caro, Jorge Isaacs, José María Quijano Wallis, Lázaro María Pérez, y el entonces secretario de Instrucción y de Exteriores, Ricardo Becerra, estuvieron entre los asistentes ${ }^{16}$. Aunque en sus comunicaciones oficiales con Chile Soffia no dio cuenta del método de convocatoria, sí informó que había logrado "reunir en su casa a los hombres de letras más importantes de todos los círculos"17. De esta manera, y a diferencia

vapor de Zalamea hermanos, 1881. Sólo en 1884, en el cargo de Ministro plenipotenciario para las repúblicas de Chile y Argentina, Samper tendrá la oportunidad de conocer personalmente al presidente Santa María.

${ }^{14}$ Ibídem. pp. 17-18.

${ }^{15}$ Para un estudio reciente sobre la relación entre saber y poder en Colombia ver: Gilberto Loaiza Cano, Poder letrado. Ensayos sobre historia intelectual de Colombia, siglos XIX y XX, Cali, Programa Editorial Universidad del Valle, 2014.

${ }^{16}$ Para un seguimiento detallado de la invitación a este mosaico y de las contestaciones, ver: Manuel J. Vega, Un poeta chileno en Bogotá. Una anécdota literaria "El Mercurio de Valparaíso", abr. 28 (1918), pp. 20-23. Esta anécdota fue reproducida en pleno por Ricardo Donoso, José Antonio Soffia en Bogotá, "Thesaurus", XXXI, 1 (1976), pp. 97-120.

${ }_{17}^{17}$ ANC, Colección DSMG, doc. C3161, Soffia a Domingo Santa María, Bogotá, octubre 12 de 1881.

Araucaria. Revista Iberoamericana de Filosofia, Política y Humanidades, año 19, $\mathrm{n}^{\circ} 38$. Segundo semestre de 2017. Pp. 495-517. ISSN 1575-6823 e-ISSN 2340-2199 doi: 10.12795/araucaria.2017.i38.22 
de otros letrados extranjeros instalados en Bogotá, Soffia no se introdujo en las formas de sociabilidad preexistentes, sino que constituyó nuevas. El diplomático leyó bien lo oportuno que podían ser estas formas de sociabilidad, estas microsociedades como les ha definido Carlos Altamirano, para darse a conocer e intercambiar y debatir todo tipo de ideas ${ }^{18}$.

Cartas posteriores muestran algunos frutos de esta inscripción de Soffia en el medio intelectual bogotano ${ }^{19}$. A comienzos de noviembre, Soffia envió a Santa María una remesa de 76 libros, 22 ellos publicados en el último año. En el inventario de los mismos, Soffia redactó breves biografías de los autores, $\mathrm{y}$ en otros casos resúmenes de las obras ${ }^{20}$. El conjunto bibliográfico enviado al presidente chileno no constituía pues una agrupación desinteresada. Se trataba, por un lado, de un conjunto representativo de la producción intelectual colombiana, que incluía textos oficiales, obras gramáticas e históricas, trabajos poéticos y científicos. Por el otro, y como revelan las múltiples semblanzas, se trataba de un conjunto previamente estudiado, que le había permitido a Soffia avanzar en su conocimiento de la política colombiana y contrastarla con la chilena. "Mucho observo y medito las instituciones de este rico país", escribía a Santa María "y cada día veo que la comparación con las nuestras nos es en todo favorable" 21 .

Con este tipo de estrategias e informes, Soffia demostraba su pericia para el servicio diplomático. Como ha subrayado Christophe Charle, los intelectuales no suelen definirse únicamente en relación con la sociedad y la cultura de la cual parten, ni con la situación política de su país, "sino de una manera más amplia, en relación con elementos internacionales de las distintas culturas o de los debates políticos"22. Durante el ejercicio diplomático, valga agregar, este tipo de definiciones pueden bien acelerarse. La práctica de difusión, recopilación, selección, y marcación de libros y lecturas, realizada por Soffia como tarea de interacción y aprendizaje, convertía al ministro chileno en actor activo del intercambio cultural y político entre dos culturas nacionales, característica que, siguiendo de nuevo a Charle, integraba el perfil del intelectual decimonónico ${ }^{23}$.

${ }^{18}$ Carlos Altamirano, Intelectuales: notas de investigación, Bogotá, Grupo Editorial Norma, 2006, pp. $125-127$.

19 Por medio intelectual entendemos, siguiendo a Christophe Prochasson, aquel conjunto de relaciones intelectuales, afectivas y, en ciertos modos, jerárquicas entre muchos actores considerados como intelectuales. Ver: Histoire intellectuelle/histoire des intellectuels: le socialisme français au début du XXe siècle, "Revue d'histoire moderne et contemporaine", 39e, 3 (1992), p. 444.

20 Sobre Miguel A. Caro, Soffia informó que era un conservador "sumamente moderado"; del Código civil colombiano de 1873, que era "calcado del Código civil chileno, menos en la parte relativa al matrimonio y el estado civil de las personas"; mientras que de los Estudios económicos y fiscales de Aníbal Galindo añadió que realizaba un buen estudio de los ferrocarriles chilenos.

${ }^{21}$ ANC, Colección DSMG, doc. C3170, Soffia a Domingo Santa María, Bogotá, septiembre 5 de 1881.

${ }^{22}$ Christophe Charle, Los intelectuales en el siglo XIX. Precursores del pensamiento moderno, Madrid, Siglo Veintiuno de España Editores, 2000, p. xxv.

23 Ídem. 
Por lo demás, las actividades adelantadas por Soffia parecieron incidir rápidamente sobre su misión. Al tiempo que convertía su casa en espacio de sociabilidad para los políticos-letrados, Soffia debió informar al gobierno colombiano la negativa de Chile de participar en el Congreso de Panamá, iniciativa en planeación que comprometía a la diplomacia argentina, venezolana y colombiana, y que buscaba crear una convención de arbitraje para finalizar la Guerra del Pacífico ${ }^{24}$. Tema sensible para el Estado chileno, la idea del congreso fue rechazada de inmediato y repelida en bloque por sus distintos consulados. El objetivo fue alcanzado para finales de 1881, momento en el que la mayor parte de países invitados, incluida Colombia, se abstuvieron de participar en el evento. Argentina y Venezuela fueron los dos únicos países que siguieron respaldando la iniciativa, el primero debido sobre todo a sus tensiones fronterizas con Chile.

La articulación entre las actividades organizadas por Soffia y el cumplimiento de sus instrucciones quedó también manifiesta en sus comunicaciones oficiales, las cuales subrayaron otro de los recursos utilizados en su misión: el mediático. De manera ejemplar en diciembre del 1881, Soffia informaba: "aquí estoy al habla con la prensa a cuyos directores me he atraído, ellos serán nuestros, en su mayor parte. La propaganda va bien [...]"25. Soffia ampliará luego esta apreciación, manifestando ahora la molestia que su exitoso accionar había causado a Rafael Núñez, otrora promotor del Congreso de Panamá. Según explicaba al jefe de Relaciones Exteriores, el haber inclinado la opinión a favor de Chile había puesto de mal humor al por entonces expresidente: "como le tenía tomadas las avenidas de la opinión y de la prensa contra su congreso, no tuvo otro desquite que su silencio primero y su resignación después" 26 .

La división planteada entre las "avenidas de la opinión" y aquellas "de la prensa" nos indica aquí los distintos pero a la vez complementarios escenarios que Soffia debió allanar. Si el segundo apelaba directamente a los papeles periódicos y sus responsables, un conglomerado que pudo cautivarse económicamente, el primero remitía al mundo político, reunido y persuadido de las bondades chilenas durante los mosaicos. En otras palabras, Soffia había logrado inclinar a su favor dos espacios fundamentales para frenar la idea del congreso panameño y su arbitraje. Dos espacios, además, conectados tanto por las fuerzas políticas e intelectuales que les lideraban, como por el impacto que podían infringir en las decisiones de gobierno. El ya comentado libro de

${ }^{24}$ Rubilar ha profundizado sobre este conflicto entre agendas diplomáticas, destacando el viaje hacia Bogotá y Caracas de Miguel Cané y Martín García Mérou, miembros de la legación argentina que buscaban lograr objetivos contrarios a los de Soffia. Desde Venezuela, será el propio presidente Guzmán Blanco quien buscará influir a favor del Congreso de Panamá y su consecuente convención de arbitraje. Véase: La política exterior de Chile durante la guerra y postguerra del Pacífico (18791891), óp. cit. pp. 363-389.

${ }^{25}$ ANC, Colección DSMG, doc. C3138, Soffia a Domingo Santa María, Bogotá, diciembre 12 de 1881.

${ }^{26}$ BNCh, Sala Medina, doc. 869816, Soffia a Luis Aldunate, Bogotá, mayo 28 de 1882, f. 286. 
Samper resulta también indicativo de esta interacción entre medios y cultura política, así como de su uso estratégico por parte de Soffia.

Ahora bien, el cumplimiento de esta meta no determinó un ceso de los movimientos de Soffia en el plano sociocultural. Preocupaba aún a Santiago el rol estadounidense en Panamá, un territorio que Chile consideraba debía permanecer bajo control suramericano, por lo que en los años siguientes las misivas de Soffia girarán sobre las actuaciones extranjeras en el Istmo ${ }^{27}$. Bajo esta nueva guía, el ministro intentó desde 1882 reforzar los lazos construidos. Quería conocer mejor las opiniones sobre el tema panameño y dejar clara la posición de su gobierno. El camino escogido para abastecerse de información y guiar la opinión fue similar al ya transitado: auspiciar a la prensa y afirmar su casa como un lugar de sociabilidad, dos estrategias a las que sumó la mediación editorial. El contexto en el que ejecutará estas tareas, sin embargo, será mucho más difícil.

\section{Trabajos para la ciudad letrada}

La administración de Francisco Zaldúa, iniciada en abril 1882 y cesada abruptamente con su muerte en diciembre del mismo año, había representado el mejor momento para el ejercicio de Soffia. Para el ministro chileno, este gobierno había constituido una fórmula estabilizadora entre el liberalismo radical y el independiente. Zaldúa había sido, además, el mandatario más abierto a su influencia en temas como el Congreso de Panamá, pues según relataba en sus misivas, este no quería "complicar a Colombia en ninguna cuestión internacional" 28 . Su muerte afectó por tanto el optimismo del ministro. Según transmitía a Santiago, sólo hombres como Zaldúa, Ancízar o Camacho Roldán se preocupaban por tener a los EEUU como garantes de la neutralidad del Canal, mientras que Núñez y los conservadores sólo mostraban desinterés frente al tema ${ }^{29}$.

El fallecimiento de Zaldúa, por otra parte, había abierto el camino para que estos últimos se acercaran de nuevo al poder, ahora de lleno con la bandera de la Regeneración, una dinámica que jalonará posteriormente el conflicto civil de 1884, un año que no tan casualmente será uno de los mayor actividad por parte de Soffia. No obstante, sus trabajos para la ciudad letrada bogotana -por traer a colación la clásica metáfora de Ángel Rama- destacarán desde 1883, y a partir de un evento especial: el centenario del natalicio de Simón Bolívar.

${ }^{27}$ Como también señala Rubilar, los informes de Soffia llevaron a la cancillería chilena a dar mayor vigilancia a la situación panameña, e inclusive, llegado el caso, a contemplar una posible defensa de los intereses colombianos ante alguna situación crítica. Ver: Guerra y diplomacia, óp. cit. p. 165.

${ }^{28}$ BNCh, Sala Medina, doc. 869816, Soffia a Luis Aldunate, Bogotá, mayo 28 de 1882, f. 286.

29 ANC, Colección DSMG, doc. C3128, Soffia a Domingo Santa María, Bogotá, enero 6 de 1882. 
Durante el clima conmemorativo asociado a esta fecha, y pese a las tensiones, Soffia auspicia el que será el homenaje editorial nacional: el Romancero Colombiano. Esta obra colectiva presentó treinta y siete composiciones de las figuras político-literarias más influyentes del país, como Miguel A. Caro, José M. Samper, José Joaquín Ortiz, José Manuel Marroquín y el mismo Rafael Núñez, todos miembros insignes del partido conservador. También participaron de esta obra los libreros Lázaro M. Pérez y Jorge Roa, y los ya afamados Rafael Pombo y Manuel M. Madiedo ${ }^{30}$.

La producción del Romancero demostró a los círculos letrados no sólo las habilidades editoriales de Soffia, quien además de sugerir el estilo de la obra, seleccionó, ordenó y llevó a la imprenta el proyecto, sino también su compromiso con la conmemoración y sus participantes. De acuerdo a sus palabras, solo 39 días le bastaron para tener listo el libro, justo para alcanzar la fecha del 24 de julio. Según recordará años después José Manuel Marroquín -futuro presidente colombiano entre 1901 y 1904- tanto él como los otros partícipes del proyecto, a sabiendas de que en las imprentas bogotanos era imposible editar un libro a tiempo, tenían "la más absoluta certidumbre" de que el Romancero no alcanzaría a publicarse, no obstante, antes del mediodía, el libro editado por Soffia ya figuraba en manos de los lectores ${ }^{31}$. Con esta empresa, afirmaba Marroquín, el ministro chileno había logrado contribuir a la celebración del Centenario bolivariano, a la vez que había despertado entre los intelectuales la afición al "hermoso y enteramente español género literario que fue menester cultivar para producir la obra" ${ }^{32}$.

Parte sin duda de la estrategia general de Soffia, este ejercicio de mediación exhibió en buena medida el conocimiento que había adquirido del elenco conservador. Por un lado, y como ya lo advertía el citado Marroquín, el género impulsado no podía ser más estimulante para un conjunto de figuras político-literarias que dominaban la gramática y la versificación, y que además abrazaban la literatura española ${ }^{33}$. Por otro lado, y como lo ha mostrado José María Rodríguez García, las composiciones del Romancero no sólo evidenciaron el clima de reconciliación con España y con la Iglesia que el proyecto regenerador alentaba, sino que vertieron una nueva lectura de Bolívar y lo bolivariano atada a los criterios ideológicos del nuevo régimen en

${ }^{30}$ De los 300 ejemplares impresos la mitad correspondió a la delegación chilena, cuestión que sin dudas orienta sobre su financiación. En: José Antonio Soffia, Romancero colombiano. Homenaje a la memoria del Libertador Simón Bolívar en su primer centenario, 1783-1883, Bogotá, Imprenta de La Luz, 1883.

31 José Manuel Marroquín, José Antonio Soffia, "El Papel Periódico Ilustrado”, 69, jun. 25 (1884), pp. 330-331.

32 Ibidem, p. 330.

33 Sobre la relación entre poder y palabra en Colombia, véase: Diego Montaña Cuéllar, Colombia: país formal y país real, Buenos Aires, Editorial Platina, 1963, pp. 7-28; y Malcolm Deas, Miguel Antonio Caro y amigos: gramática y poder en Colombia, [en: Malcolm Deas, Del poder y la gramática y otros ensayos sobre historia, política y literatura colombianas, Bogotá, Taurus, 2006], pp. $27-61$.

Araucaria. Revista Iberoamericana de Filosofía, Política y Humanidades, año 19, no 38. Segundo semestre de 2017. Pp. 495-517. ISSN 1575-6823 e-ISSN 2340-2199 doi: 10.12795/araucaria.2017.i38.22 
establecimiento, de rostro católico, silueta oligárquica y apegos hispanistas ${ }^{34}$.

Sólo para ejemplificar, el Romancero abría con el romance "Bolívar providencial", escrito por Rafael Núñez, líder político del proyecto conservador, y cerraba con uno titulado "La reconciliación", obra de Miguel Antonio Caro, la cabeza intelectual del mismo. Esta última composición celebraba por supuesto la renovada amistad colombo-española, contemplada por Caro como vital para el direccionamiento cultural del país. Soffia, por su parte, aportó el romance "Los dos mesías", que rememoraba el encuentro de Bolívar con San Martín en Guayaquil (1822), a especie de recordatorio de la unidad continental en los tiempos revolucionarios. Así, Soffia logró no sólo ganar a su favor una buena parte del universo letrado colombiano, sino servir a la proyección del proyecto conservador, en rápido ascenso al poder durante estos años.

El valor de este precedente, que ciertamente documentaba la íntima relación entre literatura y poder en Colombia, parece haber impulsado a Soffia en nuevas direcciones. En 1884, de nuevo con Núñez como presidente, el ministro chileno auspiciaría otro espacio de sociabilidad: El Ateneo. Pensado a imagen y semejanza de la famosa institución madrileña, este espacio buscaba ser "campo neutral para las opiniones políticas y las creencias religiosas, donde se trabajará solo por el bien y el engrandecimiento de la patria" ${ }^{35}$. El papel de Soffia en su creación fue a todas luces principal. El Conservador habló del Ateneo como "su iniciativa", mientras que el Papel Periódico Ilustrado dedicó a Soffia su edición de junio, publicando en esta algunas actas del Ateneo justamente por deber éste "su creación y organización al ilustrado señor Soffia"36.

Como presidente honorario, Soffia tuvo a su cargo el discurso de apertura, donde manifestó su deseo de que el Ateneo sirviese para fraternizar las fuerzas políticas en disputa, en creciente rivalidad desde la vuelta de Núñez al poder. Situado entre Santiago Pérez y José Joaquín Ortiz, representantes de los partidos antagónicos, Soffia manifestaría lo siguiente:

"En nuestra América los albores del siglo fueron de lucha y de heroísmos, sus promedios han sido de organización y controversia: ¿estarán llamados sus postreros lustros, ya ricos en experiencia, a la solución tranquila de los graves problemas cuyos factores han quedado de hecho establecidos?...¿ No será esta culta capital la llamada, por la vasta ilustración y el clarísimo ingenio de sus hijos, la llamada a dar a sus hermanas el saludable ejemplo de agrupar a los ciudadanos en instituciones como ésta, ajenas a las exaltaciones del comicio y a la disolvente bandería de otros Clubs?" ${ }^{37}$.

${ }^{34}$ José María Rodríguez García, La Regeneración sin la Revolución: Caro contra Bolívar, "Revista Hispánica Moderna”, 60, 1, (2007), p. 99. Un proceso de translatio similar al ocurrido con Bolívar podría localizarse en la ya analizada biografía de Santa María que interesadamente elaboró Samper.

${ }_{35}$ Ateneo de Bogotá, "El Conservador", 457, jun. 28 (1884), p. 1.826.

36 José Manuel Marroquín, óp. cit. p. 331.

37 José Antonio Soffia, Discurso del presidente honorario del Ateneo de Bogotá, "El Ateneo. Órgano oficial del Ateneo de Bogotá", 1, enero (1885), p. 15. Las palabras de Soffia, elocuentes sobre sus 
Los interesantes interrogantes de Soffia no tendrían, sin embargo, las respuestas esperadas. La dinámica del Ateneo no logró frenar las tensiones y su propia vida como espacio académico no se prolongó más allá de enero 1885 , mes en el cual un levantamiento liberal desataba una nueva guerra civil. Según relato de José María Quijano Wallis, "la conmoción producida por la guerra hizo suspender las labores y sesiones del Ateneo. Muchos de sus miembros se fueron a los campamentos; otros tuvieron que ocultarse para evitar empréstitos y persecuciones [...] la brillante asociación tocó la dispersión". Ni con la vuelta de la paz, recordaba Quijano, "fue posible reunir las tribus dispersas. Algunos de los socios habían muerto y otros se hallaban expatriados" 38 .

La caída de este proyecto afectó los ánimos de Soffia. Sus comunicaciones a Santiago durante este periodo dieron cuenta de su impotencia frente a los acontecimientos, así como de un examen cada vez más negativo del gobierno de Núñez. En paralelo, sin embargo, las buenas relaciones que aún cultivaba le proveyeron protección frente a los problemas, incluso a los surgidos en su país natal, y garantizaron la continuidad de sus actividades sociales y culturales.

Sobre lo primero, destaca que a finales de 1884 , y en respuesta a una editorial del periódico chileno El Independiente, los redactores de El Conservador de Bogotá hayan salido en su defensa. El periódico santiaguino atacaba el rol de Soffia, manifestando que este incurría en gastos enormes debido a sus esfuerzos por cultivar las letras en Colombia, y que en el nuevo escenario de paz que vivía Chile su cargo era innecesario. Replicaba El Conservador que en la diplomacia moderna "la ciencia, la conveniencia oficial y el interés de los pueblos" no estaba ya en alentar las suspicacias, las amenazas o las astucias: "Hoy los gobiernos escogen para sus cancillerías hombres honrados, inteligentes, galantes y sobre todo, benévolos"39.

El aprecio logrado por Soffia en la capital, aún en la crisis de 1885, era pues palpable. Fuentes singulares como el álbum de Recuerdos de Lastenia Soffia, esposa del ministro, comprueban además la continuidad de las veladas en su casa, al incluir numerosas poesías ilustradas de personalidades como José Joaquín Ortiz, Agripina Samper, Dorila A. de Rojas, Alejandro Calvo y Antonio Gómez Restrepo, todas firmadas durante este periodo ${ }^{40}$. También elocuente de

ambiciones, fueron leídas con claridad por figuras como Marroquín. En su retrato biográfico, este afirmó que más allá de impulsar las ciencias o las artes, Soffia aspiraba a que el Ateneo ejerciera "una acción conciliadora dando ocasiones para que los hombres distinguidos y estudiosos, por muy separados que los tenga la política, se encuentren en un campo neutral en que, olvidadas siquiera momentáneamente nuestras contiendas, sientan unos por otros la estimación que raras veces deja de engendrar el trato, y se habitúen á ser colegas, camaradas y hasta amigos fuera del campo de la política, aunque en éste se traten como decididos adversarios”. En: José Manuel Marroquín, José Antonio Soffia, óp. cit. p. 331.

38 José María Quijano Wallis, Memorias autobiográficas, histórico-políticas y de carácter social, Grottaferrata, Tipografía Italo-Orientale, 1915, pp. 481-482.

${ }^{39}$ La legación chilena en Colombia, "El Conservador", 536, nov. 11 (1884), p. 2.142.

${ }^{40}$ Lastenia Soffia de Soffia, Recuerdos, álbum manuscrito e ilustrado, Biblioteca Luis Ángel Arango, Sección Libros raros y manuscritos. 
la estima existente hacia Soffia fue el obsequio que recibió de parte del artista gráfico Lázaro María Girón, quien realizó una edición manuscrita e ilustrada de Las cartas de mi madre, la más famosa composición de Soffia. Hoy resguardado en la Biblioteca Nacional de Chile, este "exemplar único" incluyó retratos de María Josefa Argomedo, de Lastenia Soffia y del propio ministro chileno ${ }^{41}$.

El año de 1885 sería también clave para la propia trayectoria poética de Soffia, quien sobre el mes de abril vio publicada su obra Poemas y poesías. Prologada por José Manuel Marroquín, esta compilación de sus más famosas composiciones escritas en Chile y Colombia sería auspiciada por la Librería Torres Caicedo de Lázaro M. Pérez, e impresa en Londres por Juan M. Fonnegra. Llena de dedicatorias a hombres y mujeres que le acompañaron en veladas y tertulias, y con más de 500 páginas, Poemas y poesías fue el libro más prolijo de Soffia publicado en vida ${ }^{42}$.

Antes de su muerte, ocurrida en marzo de 1886, Soffia había incluso comenzado nuevos proyectos editoriales, siendo el más destacado el realizado junto a José Rivas Groot, con quien empezó a recopilar traducciones al castellano de la obra poética de Víctor Hugo. Ideada a propósito de la muerte del escritor francés en 1885, la compilación sería publicada en 1889 por la casa editorial de Medardo Rivas, llevando el título: Victor Hugo en América. Traducciones de ingenios americanos. Dueña de un largo estudio preliminar a cargo de Rivas Groot, esta antología reunió más de un centenar de composiciones traducidas por hombres y mujeres de letras hispanoamericanos -pese al anuncio del subtítulo- entre los que destacaban Andrés Bello, Felipe Pardo y Aliaga, José Joaquín de Mora, Isabel A. Prieto de Landázuri, Carlos Arturo Torres, Ricardo Palma, Rafael Pombo, Teodoro Llorente, Miguel A. Caro, Rafael Núñez, y el propio Soffia ${ }^{43}$.

En relación al poder de convocatoria del poeta chileno, Germán Arciniegas señaló en 1969, en la introducción a una nueva edición del Romancero, rebautizado con el apellido Bolivariano, que Soffia era "como el director de la gran orquesta lírica que formaban en la segunda mitad del siglo XIX los poetas colombianos" $"$.

\footnotetext{
${ }^{41}$ José Antonio Soffia, Las cartas de mi madre (edición manuscrita por Lázaro María Girón), Bogotá, 1885, Biblioteca Nacional de Chile, sala Medina.

42 José Antonio Soffia, Poemas y poesías de J. A. Soffia, Londres, Juan M. Fonnegra, 1885. El prólogo de Marroquín fue el mismo texto que poco antes había aparecido en el Papel Periódico Ilustrado.

43 Durante 1886, aparecerá también publicada una traducción de Soffia del poema "Los Zarcillos" de François Coppée, la cual estará dedicada al Ministro colombiano de Relaciones Exteriores: Mariano Tanco.

${ }^{44}$ Germán Arciniegas, Este Romancero [en Romacero Bolivariano, Caracas, Italgráfica, C. A., 1969], p. 10.
} 


\title{
Crisis e inconformidad
}

Los últimos meses de Soffia en Bogotá fueron turbulentos. Mientras más era admirada su figura, debido sobre todo a su activismo cultural, más pesimista se hacía su mirada del país político. A inicios de 1885, por ejemplo, ya lanzada la Guerra Civil, el ministro chileno transmitió a Santiago la siguiente impresión: "La Arcadia se nos volvió un campo de Agramante y la égloga dejeneró en tragedia" ${ }^{45}$. Con el paso de los meses estas observaciones se volverán recurrentes. En sus reportes, Soffia informaba que el conflicto se debía a las medidas de Núñez frente a la Asamblea del Estado de Santander en 1884, que provocaron la renuncia de sus secretarios y dieron motivos a los liberales para rebelarse. Según el ministro, la ley marcial más absoluta había sido puesta en vigor y "reducida a nada por un mero decreto ejecutivo, la decantada Constitución más liberal del más liberal de los pueblos del nuevo continente" ${ }^{" 46}$.

Molestaba además a Soffia la actitud del gobierno frente a las delegaciones extranjeras, ilustrando para ello el caso del representante paraguayo, a quien por firmar una protesta sobre soldados muertos en martirio le fue "cancelado su exequatur" ${ }^{\prime 4}$. En una serie de cartas dirigidas entre junio y agosto de 1885, un Soffia irritado comentaba sobre la guerra:

\begin{abstract}
"Sus resultados serán la reforma constitucional, la mayor duración de los periodos presidenciales, la paz con Roma... y la muerte de los "Estados Soberanos"; que hacían de este país nueve hidras, o mas bien un chacal de nueve fauces. ¡Pero a que duro precio se hará esto, si llega a hacerse!... La bandera nacional humillada por la de las infinitas estrellas, la propiedad particular anulada, los derechos personales desconocidos [...]"48.
\end{abstract}

La referencia a los EEUU la explicaba su rol en los acontecimientos de Colón de abril de 1885, cuando un cuerpo de marines desembarcó sobre dicha ciudad, como si fuese propia, para imponer el orden. El hecho preocupó a todos los cónsules menos al gobierno colombiano, que de acuerdo con Soffia, no estimó la presencia de los yankees como un peligro ${ }^{49}$. Aquí Soffia se atrevió a conjeturar: "Parte de mis temores sobre la seguridad del Istmo [...] se han realizado. La eterna lucha de los partidos está llamando a gritos a los extranjeros para que se hagan dueños de aquella zona, y estos parecen ya tentados a aprovecharse de la oportunidad que se les ofrece" $" 50$.

${ }^{45}$ ANC, Colección DSMG, doc. B0094, Soffia a Domingo Santa María, Bogotá, marzo 2 de 1885, f. 219-219v.

${ }^{46}$ Ibídem, f. 222.

${ }^{47}$ Ibídem, f. $223 \mathrm{v}-224$.

${ }^{48}$ ANC, Colección DSMG, doc. B4373, Soffia a Domingo Santa María, Bogotá, junio 30 de 1885.

${ }^{49}$ ANC, Colección DSMG, doc. B0092, Soffia a Domingo Santa María, Bogotá, abril 20 de 1885, f. 238 .

50 Ídem. 
La inconformidad de ministro se debía también en su lectura de los movimientos de Núñez y de los conservadores. Estimaba que su permisividad frente a los EEUU respondía a la necesidad de financiar la guerra. "El gobierno había perdido las aduanas y las vías de comunicación”, contaba a Santiago en agosto de 1885, por lo que en sus apuros no habían visto "otro medio de salvación que el de echarse en brazos de los yankees..."51. De la misma forma, un viaje a Washington de los conservadores Jorge Holguín y Lázaro M. Pérez fue visto como una misión que buscaba dinero y $\operatorname{armas}^{52}$. Convertidos los norteamericanos en acreedores, afirmaba Soffia, "cobrarán caro su auxilio" y serán "tutores de esta antigua Colombia [...] Se adueñarán de parte de sus tierras y serán sus árbitros los mismos que solo pensarán en su absorción" 53 . Con este panorama, Soffia hizo manifiesta su intención de abandonar Bogotá:

"Aconseje a los pocos descontentos se vengan para acá. Aquí hai iglesia libre
y obispos autócratas; el Gobierno no se preocupa de hacer respetar sus fueros
y derechos políticos ni sociales; una pistola es el compendio de las garantías
individuales; y la propiedad particular pasa a ser botín del Gobierno. Siempre
que no hai dinero en caja. Verdad es que los extranjeros vivimos desesperados y
dando un siglo de vida en esta atmosfera de pólvora y gritos. Confío, mi querido
señor, en que ya para nosotros no será larga la permanencia por acá [...]!" ${ }^{4}$.

Los reclamos continuaron en otras cartas y obtuvieron la respuesta esperada en noviembre de 1885, cuando le fue informado a Soffia su traslado como ministro para Brasil y la Argentina. La prensa local tardó en conocer esta decisión. Apenas en febrero en 1886, el periódico La Nación informó sobre la partida de la legación chilena. Según la nota, era por razones de economía que la plenipotencia chilena sería suprimida y Soffia enviado a las repúblicas del Plata $^{55}$.

Como era previsible, la nota también lamentaba el hecho. Expresaba que Soffia había figurado en Bogotá de dos maneras simpáticas: como centro de sociabilidad y como amigo y servidor de las letras. El hogar del poeta fue descrito como un "centro permanente de relaciones", mientras que su apoyo a las letras fue repasado casi en pleno:

"A él debemos la creación de nuestro Romancero Colombiano, que es un monumento patriótico, la principal iniciativa y los mayores esfuerzos en la fundación de nuestro Ateneo, una colaboración eficaz en la Academia Colombiana y en nuestra prensa literaria y científica; una protección decidida,

\footnotetext{
${ }^{51}$ ANC, Colección DSMG, doc. B4907, Soffia a Domingo Santa María, Bogotá, agosto 4 de 1885.

52 ANC, Colección DSMG, doc. B0092, óp. cit. f. 239.

${ }_{53}$ Carta de Soffia a Aniceto Vergara, Bogotá, junio 2 de 1885. Citado por Ricardo Donoso, óp. cit. p. 147.

${ }^{54}$ ANC, Colección DSMG, doc. B0094, óp. cit. f. 225.

${ }_{55}$ Colombia. La legación de Chile, "La Nación”, feb. 1886, republicado por el "El Mercurio de Valparaíso", 17.778, abr. 26 (1886), p. 4.
} 
dada a varios de nuestros calígrafos y artistas, la más asidua asistencia a todo linaje de actos públicos exhibidos en honor de la instrucción y de la educación [...], y no pocos trabajos recogidos y coleccionados con la mira de hacerlos conocer en Chile y otros países" ${ }^{56}$.

Finalizaba el autor de la nota agregando que, para la sociedad bogotana, la ausencia de Soffia y de su familia sería algo como "una dolorosa amputación moral" 57 . Dicha amputación, sin embargo, llegará antes de lo previsto y de una forma inesperada. El 11 de marzo de 1886, un infarto fulminante dio término a la vida de José Antonio Soffia en plena vía pública. La noticia provocó por supuesto la inmediata reacción de las autoridades. El gobierno colombiano decretó tres días de duelo nacional y destinó fondos para cubrir todos los gastos fúnebres asociados. Se decretó adicionalmente que el ejército rindiera al cadáver honores militares equivalentes a los de un general, y que se realizaran tres días de retretas fúnebres en la plaza de Bolívar ${ }^{58}$.

Según informe de Manuel J. Vega, secretario de la legación, las exequias oficiales de Soffia se llevaron a cabo el 13 de marzo en la Iglesia Metropolitana, en presencia del arzobispo, del nuncio apostólico, de los cuerpos diplomáticos y de "un numeroso y escogido concurso de vecinos" 59 . Entre los discursos pronunciados durante la ocasión, reproducidos luego en el periódico La Nación, destacaron el de José M. Samper, a nombre del parlamento; el de José M. Quijano Wallis, en nombre del Ateneo; el de Rafael Pombo, dado en nombre de la Academia Colombiana; y el del poeta Numa Pompilio Llona, quien oficiaba como plenipotenciario del Ecuador. La pompa fúnebre, como la calificó en su estudio Raúl Silva Castro, fue excepcionalmente solemne ${ }^{60}$.

La despedida dada a Soffia respondía, ciertamente, tanto al tipo de amistades cultivadas, como a las iniciativas que había dirigido o acompañado durante su estancia, de entre las cuales el Ateneo alcanzará la mayor recordación ${ }^{61}$. No obstante, el talante de la despedida exhibió también el desconocimiento de las opiniones de Soffia sobre la política colombiana y, sobre todo, su ansiedad por abandonar un país cuyo estado le parecía angustioso. Ninguna de las inconformidades del ministro chileno, tanto frente a Núñez y los cuadros conservadores - de cuyos grandes referentes pudo siempre rodearse- como frente al poder mantenido por la Iglesia, fueron advertidas.

56 Ídem.

57 Ídem.

${ }^{58}$ Raúl Silva Castro, Introducción, óp. cit. p. 98.

${ }_{59}$ Manuel J. Vega, Don José Antonio Soffia, "El Mercurio de Valparaíso”, 17.700, may. 10 (1886), p. 2.

${ }^{60}$ Raúl Silva Castro, Introducción, óp. cit. p. 98.

${ }^{61}$ Según manifestará Numa P. Llona, Soffia confiaba que con el Ateneo las individualidades de los partidos militantes aprenderían a conocerse mejor y a estimarse mutuamente. Ver Silva Castro, José Antonio Soffia (1843-1886), óp. cit. p. 122. 
Si algo quiso Soffia al final de su periplo fue alejarse de un medio con el compartía aficiones pero muy poco en términos de manejo político. Irónicamente, sus restos tardaron más de tres lustros en trasladarse a Chile. Lo harán apenas en 1903, año en el que los miembros de la Gruta Simbólica, por entonces el principal círculo intelectual bogotano, realizarán una última velada en su honor ${ }^{62}$.

\section{Conclusiones}

El impacto de las actividades diplomáticas de José Antonio Soffia en la capital colombiana resulta no obstante difícil de dilucidar por completo. De sus múltiples contribuciones en el ramo editorial, en el quehacer literario o en la animación de espacios de sociabilidad, son muchos los detalles que permanecen oscuros. La manera en que protegió decididamente a los calígrafos y artistas, como señaló el redactor de La Nación, deja por ejemplo varios interrogantes abiertos, si bien la cercanía de Soffia con Lázaro María Girón resulte orientativa. Del mismo modo, carecemos de datos como la frecuencia de las reuniones o eventos organizados en su residencia, o de un listado de los participantes más constantes. A su vez, y en comparación con las comunicaciones enviadas a Chile, son casi inexistentes en los archivos los intercambios epistolares o las notas intercambiadas con interlocutores colombianos, por lo que muchos detalles sobre su misión, su accionar intelectual o simplemente sobre su vida cotidiana se nos escapan.

De todas formas, resulta claro que estamos ante una silueta intelectual activa y multifacética, cuyo estudio permite exponer la variedad de recursos puestos en juego al momento de adelantar misiones diplomáticas complejas. Potenciar la comunicación y el intercambio cultural entre Chile y Colombia fue para Soffia su manera de abrirse camino entre las rivalidades políticas colombianas, uniformadas en sus gustos literarios y hábitos sociales. Trabajar con y para el universo letrado fue asimismo la manera en que logró ganar su confianza. El impulso dado a los distintos proyectos editoriales aquí descritos, adelantados de manera colectiva e individual, ilustran no sólo un interés particular por dinamizar el espacio literario, sino también una lectura del medio en el que se situaba y una clara opinión sobre cuáles eran los mecanismos más idóneos para seducirlo.

La apertura de espacios de sociabilidad formales, como el Ateneo, o la consolidación de su casa como "centro de relaciones", exponen por otra

\footnotetext{
${ }^{62}$ Programa de la velada literaria organizada por la Gruta Simbólica, en honor del distinguido literato chileno José Antonio Soffia, 14 de abril de 1903, Biblioteca Nacional de Colombia, hoja suelta.
} 
parte un interés por construir una opinión favorable hacia su persona, y en consecuencia hacia los objetivos chilenos en un contexto de postguerra regional. En este nivel, los usos público-privados de la escritura y del recurso lírico se convirtieron en los factores primordiales para avanzar en los objetivos trazados, complementándose con el respaldo al gremio periodístico y a los artistas e ilustradores, dueños para este momento de un prestigio en el espacio editorial. Dicho de otro modo, Soffia logró aprovechar la estrecha relación existente entre poder y escritura en Colombia para alcanzar los principales objetivos de su misión. Le bastó atender los gustos literarios de las élites rectoras, apoyar la publicación de sus composiciones, y abrirles espacios para que las ensayaran abiertamente, como bien ocurría en los mosaicos, espacios que para Soffia debían servir para el diálogo entre los grupos políticos opuestos.

El éxito de Soffia -y también de la política internacional chilena- reposó pues en una serie de ejercicios dirigidos a cautivar un bloque social específico, aquel que se movilizaba entre la palabra declamada y la impresa, ambas arropadas de autoridad en la Colombia de finales del siglo XIX. Fundamentales para el ministro chileno, estos ejercicios le abrieron además la oportunidad de publicar y dar a conocer sus propias composiciones, que sumando a su reconocimiento y prestigio literario, se convirtieron en el único logro particular conseguido en un medio donde las letras y la intransigencia iban de la mano. 


\section{Referencias bibliográficas:}

Altamirano, Carlos, Intelectuales: notas de investigación, Bogotá, Grupo Editorial Norma, 2006.

Arciniegas, Germán, "Este Romancero", en Romancero Bolivariano, Caracas, Italgráfica, C. A., 1969, pp. 9-16.

Charle, Christophe, Los intelectuales en el siglo XIX. Precursores del pensamiento moderno, Madrid, Siglo Veintiuno de España Editores, 2000.

Deas, Malcolm, "Miguel Antonio Caro y amigos: gramática y poder en Colombia", en Malcolm Deas, Del poder y la gramática y otros ensayos sobre historia, política y literatura colombianas, Bogotá, Taurus, 2006, pp. 27-61.

Donoso, Ricardo, "José Antonio Soffia en Bogotá", en Thesaurus, XXXI, 1, 1976, pp. 84-159.

Loaiza Cano, Gilberto, Poder letrado. Ensayos sobre historia intelectual de Colombia, siglos XIX y XX, Cali, Programa Editorial Universidad del Valle, 2014.

Marroquín, José Manuel, "José Antonio Soffia", en El Papel Periódico Ilustrado, 69, jun. 25, 1884, pp. 330-331.

Montaña Cuéllar, Diego, Colombia: país formal y país real, Buenos Aires, Editorial Platina, 1963.

Myers, Jorge, "Los intelectuales latinoamericanos desde la colonia hasta el inicio del siglo XX", en Carlos Altamirano, dir., Historia de los intelectuales en América Latina, volumen I, Buenos Aires, Katz Editores, 2008, pp. 29-50.

Ory, Pascal, "Introduction”, en Anne Dulphy, Robert Frank, Marie-Anne MatardBonucci y Pascal Ory, Dir., Les relations culturelles internationales au XXe siècle. De la diplomatie culturelle à l'acculturation, Bruselas, P.I.E. Peter Lang, 2010, pp. 15-23.

Prochasson, Christophe, "Histoire intellectuelle/histoire des intellectuels: le socialisme français au début du XXe siècle", en Revue d'histoire moderne et contemporaine 39e, 3 1992, pp. 423-448.

Quijano Wallis, José María, Memorias autobiográficas, histórico-políticas y de carácter social, Grottaferrata, Tipografía Italo-Orientale, 1915.

Rodríguez García, José María, "La Regeneración sin la Revolución: Caro contra Bolívar", en Revista Hispánica Moderna 60, 1, 2007, pp. 79-108.

Rubilar, Mauricio, "Guerra y diplomacia: las relaciones chileno-colombianas durante la guerra y postguerra del Pacífico (1879-1886)”, en Revista Universum 19, 1, 2004, pp. 148-175. 
Rubilar, Mauricio, La politica exterior de Chile durante la guerra y postguerra del Pacífico (1879-1891): las relaciones con Estados Unidos y Colombia. Diplomacia, opinión pública y poder naval, Tesis para optar al Grado de Doctor por la Universidad de Valladolid, Valladolid, 2012.

s. a. "Ateneo de Bogotá", en El Conservador, jun. 28, 1884, p. 1.826.

s. a. "Colombia. La legación de Chile", en La Nación, feb. 1886. Citado por El Mercurio de Valparaíso, abr. 26, 1886, p. 4.

s. a. "La legación chilena en Colombia", en El Conservador, nov. 11, 1884, p. 2.142 .

Samper, José María, Chile y su presidente (Rasgo político-biográfico), Bogotá, Imprenta de vapor de Zalamea hermanos, 1881.

Silva Castro, Raúl, "Introducción", en Poemas y poesías de José Antonio Soffia. Selección y estudio crítico por Raúl Silva Castro, Santiago de Chile, Imprenta Universitaria, 1950.

Silva Castro, Raúl, José Antonio Soffia (1843-1886), Santiago, Andrés Bello, 1968.

Soffia, José Antonio, Romancero colombiano. Homenaje a la memoria del Libertador Simón Bolivar en su primer centenario, 1783-1883, Bogotá, Imprenta de La Luz, 1883.

Soffia, José Antonio, "Discurso del presidente honorario del Ateneo de Bogotá”, en El Ateneo. Órgano oficial del Ateneo de Bogotá, 1, ene. 1885, pp. 14-15.

Soffia, José Antonio, Poemas y poesías de J. A. Soffia, Londres, Juan M. Fonnegra, 1885.

Soffia, José Antonio, Las cartas de mi madre (edición manuscrita por Lázaro María Girón), Bogotá, 1885.

Soffia, José Antonio y José Rivas Groot, Victor Hugo en América. Traducciones de ingenios americanos, Bogotá, Casa editorial de Medardo Rivas y C., 1889.

Sorá, Gustavo, "Édition et politique. Guerre froide dans la culture latinoaméricaine des années 60", en Claude Hauser, Thomas Loué, Jean-Yves Mollier y François Vallotton, Eds., La diplomatie par le livre: Réseaux et circulation internationale de l'imprimé de 1880 à nos jours, París, Nouveau Monde, 2010, pp. 89-113.

Urrego, Miguel Ángel, Intelectuales, Estado y Nación en Colombia. De la guerra de los mil días a la constitución de 1991, Bogotá, Siglo del Hombre Editores - Universidad Central-DIUC, 2002.

Vega, Manuel J., "Un poeta chileno en Bogotá. Una anécdota literaria”, en El Mercurio de Valparaíso, abr. 28, 1918, pp. 20-23. 


\section{Archivos consultados}

Archivo Nacional de Chile (ANC), Colección Domingo Santa María González. Biblioteca Luis Ángel Arango, Sección Libros raros y manuscritos.

Biblioteca Nacional de Chile (BNCh), Sala Medina.

Biblioteca Nacional de Colombia (BNC). 
